\title{
Spermatic Cord Obstruction
}

National Cancer Institute

\section{Source}

National Cancer Institute. Spermatic Cord Obstruction. NCI Thesaurus. Code C78624.

Blockage of the normal flow of the contents of the spermatic cord. 